\title{
Electromagnetic Interferences in Inverter-Fed Induction Motor Drives
}

\author{
Stanislav Bartos, Ivo Dolezel, Jakub Necesany, Jiri Skramlik and Viktor Valouch \\ Institute of Thermomechanics ASCR, Dolejskova 5, 18200 Praha 8, Czech Republic \\ E-mail: dolezel@it.cas.cz, skramlik@it.cas.cz, valouch@,it.cas.cz
}

\begin{abstract}
The paper deals with the numerical modeling of a pulse-width modulated voltage inverter-fed induction motor drive for the common and differential current modes. The proposed model of the drive respects the influence of the feeding cable described by the lumped or distributed parameters. The theoretical analysis is supplemented by results of relevant simulations and experiments. Evaluated are also the frequency characteristics of selected parts of the system and their contributions to its resultant harmonic spectra.

Keywords: Electromagnetic interferences, IGBT, IGCT, inverter, induction motor, frequency characteristics
\end{abstract}

\section{INTRODUCTION}

The pulse-width modulated (PWM) transistor inverters supplying the induction motor drives often become sources of the common and differential mode currents that produce conducted and radiated electromagnetic interferences (EMI), bearing currents and decrease of the insulation lifetime. Their undesirable effects may effectively be reduced by different ways that have recently been developed, see, for example, [1][4].

The analysis of the amplitudes and harmonic spectra of the above parasitic currents requires adequate models of inverterfed induction motor (IM) [5]-[13]. The paper deals with the models of a PWM voltage inverter-fed induction motor drive developed for the common and differential current modes. Both representations of the drive system take into account models of the feeding cable with lumped or distributed parameters. The theoretical analysis is supplemented by results of relevant simulations and experiments carried out on IGBT and IGCT inverters. Evaluated are also the frequency characteristics of selected parts of the system and their contributions to its resultant harmonic spectra.

\section{THE BASIC MOdels}

The basic arrangement of the investigated system is shown in Fig. 1.

\section{A. Induction motor model for high frequencies}

The IM is modeled by the developed equivalent circuit consisting of a set of lumped parameters (see Fig. 2) determined by constrained optimization process based on the minimum difference between the calculated and measured frequency characteristics of the circuit. The circuit (we have used $n=2$ ) consists of two parts, which are similar in their structures but generally different in the values of particular parameters. The individual stator phases are modeled by two impedances $Z_{\mathrm{v} 1}$ and $Z_{\mathrm{v} 2}$ connected in series.

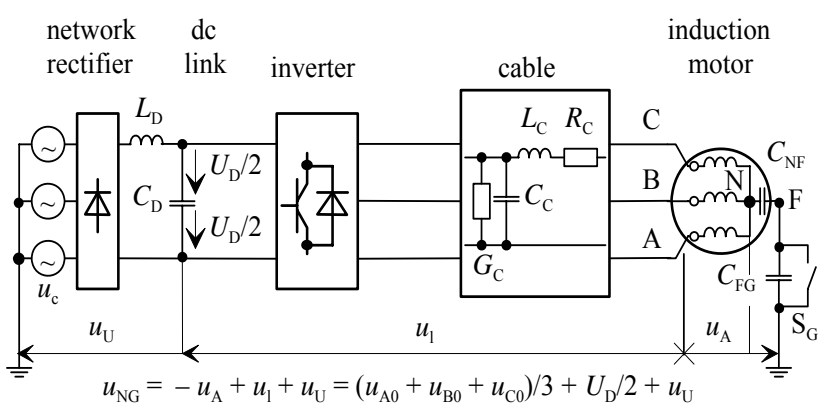

Fig. 1. The investigated drive system with an inverter, cable and IM

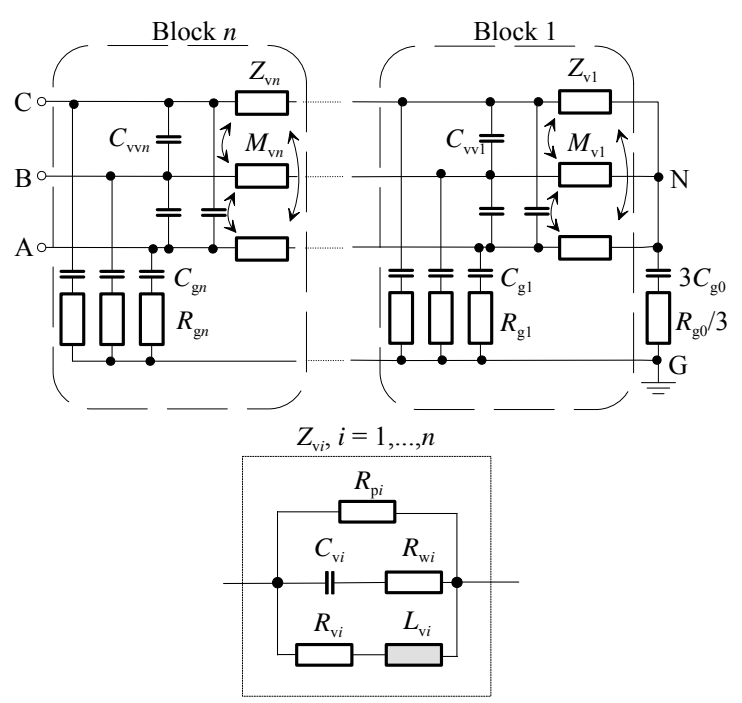

Fig. 2. Possible equivalent circuit of the induction motor

Thus, we can derive the transfer functions (IM impedances) for the common and differential modes on the basis of Fig. 2. The common mode currents flow through leakage capacitances to the earth and back to the ac power mains via the ground connection, while differential mode currents close themselves only in the phase conductors.

The influence of the mutual inductances $M_{\mathrm{v} i}$ may be incorporated into the transfer functions $Z_{\mathrm{v} i}(p), i=1,2$ by putting $L_{\mathrm{vci}}=L_{\mathrm{vi}}+2 M_{\mathrm{v} i}$ in the common mode and $L_{\mathrm{vd} i}=L_{\mathrm{v} i}-M_{\mathrm{vi}}$ in the differential mode. 
Both common and differential mode transfer functions $Z_{\mathrm{c}}(p), Z_{\mathrm{d}}(p)$ are then given by fractions containing polynomials of the seventh or eighth orders in their numerators and denominators.
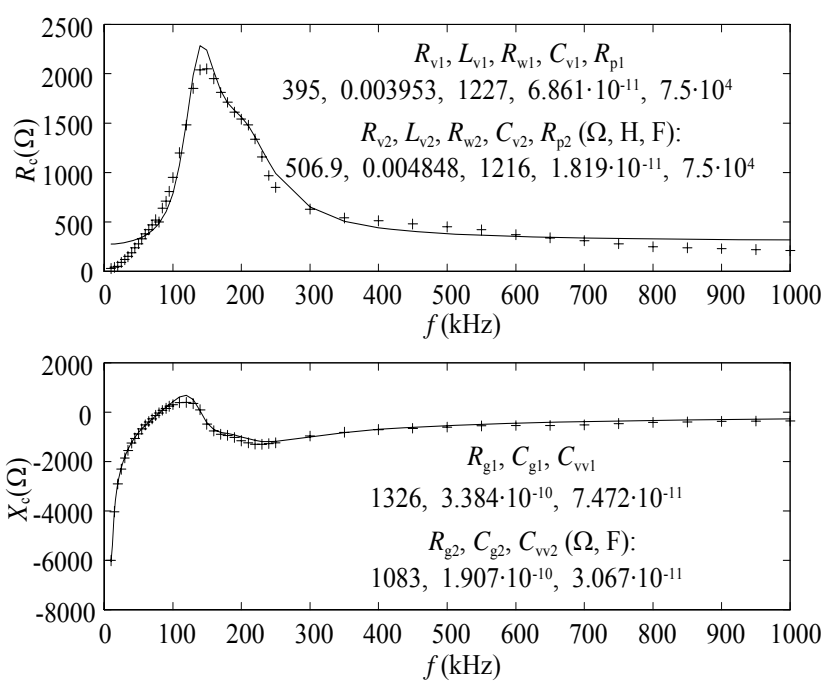

a)
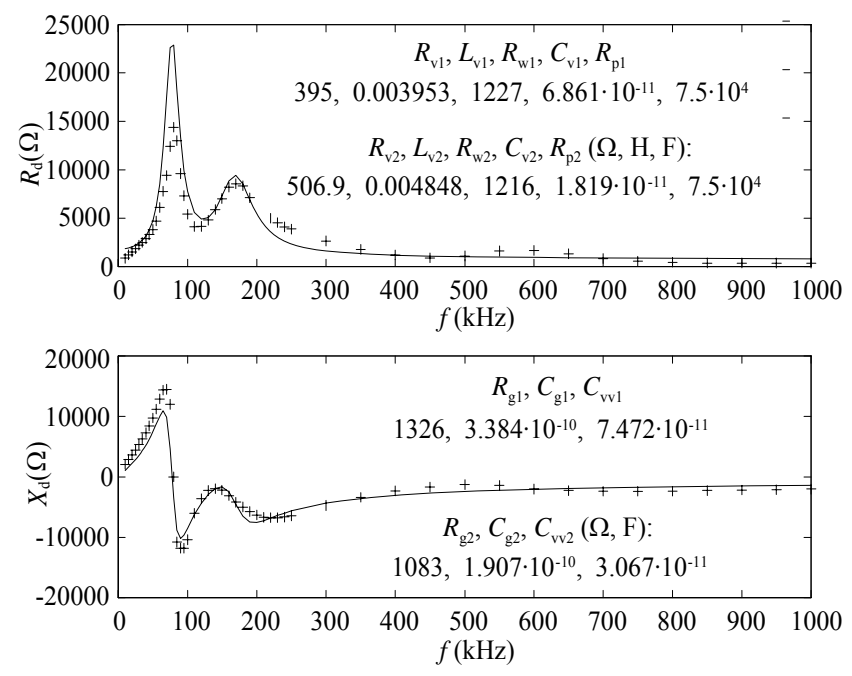

b)

Fig. 3. Real and imaginary parts of the IM impedance in the a) common mode, b) differential mode

Fig. 3 shows both measured points and calculated frequency characteristics of the real $R_{\mathrm{c}}(f)$ and imaginary $X_{\mathrm{c}}(f)$ parts of the IM impedance in the common mode (a), and $R_{\mathrm{d}}(f), \quad X_{\mathrm{d}}(f)$ in the differential mode (b). The basic IM parameters in this case are $P=1.5 \mathrm{~kW}, U=380 / 220 \mathrm{~V}$, $f=50 \mathrm{~Hz}, n=1410 / \mathrm{min}, I=3.6 / 6.2 \mathrm{~A}, \cos \varphi=0.82$.

Note that the IM model with only one set of parameters in $Z_{\mathrm{v} i}(p), i=1,2$ was obtained, valid for both the modes. Let us also emphasize that all important resonant peaks in both models may be found by the IM equivalent model shown in Fig. 2.

\section{B. Feeding cable model}

The voltage and current distributions in a system consisting of $n$ conductors are described by the following set of equations

$$
\begin{aligned}
& \frac{\partial[\boldsymbol{u}]}{\partial x}=-\left[\boldsymbol{R}^{\prime}\right][\boldsymbol{i}]-\left[\boldsymbol{L}^{\prime}\right] \frac{\partial[\boldsymbol{i}]}{\partial t} \\
& \frac{\partial[\boldsymbol{i}]}{\partial x}=-\left[\boldsymbol{G}^{\prime}\right][\boldsymbol{u}]-\left[\boldsymbol{C}^{\prime}\right] \frac{\partial[\boldsymbol{u}]}{\partial t}
\end{aligned}
$$

where $[\boldsymbol{u}]$ is a vector of the phase voltages, $[\boldsymbol{i}]$ a vector of the phase currents, $\left[\boldsymbol{R}^{\prime}\right]$ is a diagonal matrix containing resistances of individual conductors per unit length and $\left[\boldsymbol{L}^{\prime}\right],\left[\boldsymbol{G}^{\prime}\right]$ and $\left[\boldsymbol{C}^{\prime}\right]$ are dense and symmetric matrices containing inductances, modified conductances and capacitances per unit length. The initial conditions read

$$
\boldsymbol{u}(0, t)=\boldsymbol{U}(t)
$$

while conditions at the end of the line depend on how the load is modeled and connected.

Although a number of more or less sophisticated methods were developed and studied, we used only the Fourier decomposition procedure that represents a relatively simple tool for determining the time dependence of the steady state parasitic currents. The method has been incorporated into a program package written by the authors that is intended for solution of steady state and transient phenomena in systems containing feeding lines.

In case of the simplest cable representation by a lumped parameter circuit $\left(R_{\mathrm{c}}, G_{\mathrm{c}}, L_{\mathrm{c}}, C_{\mathrm{c}}\right)$, the common and differential mode transfer functions $Z_{\mathrm{cc}}(p)$ and $Z_{\mathrm{dc}}(p)$ of the cablemotor system are given by fractions with polynomials both in the numerator and denominator. These polynomials are of the order of $8 / 7$ for $Z_{\mathrm{cc}}$ and $9 / 8$ for $Z_{\mathrm{dc}}$, respectively, and can be written as

$$
Z_{\mathrm{cc}}(p)=\frac{1}{3}\left(R_{\mathrm{c}}+p L_{\mathrm{c}}\right)+Z_{\mathrm{c}}(p)
$$

and

$$
Z_{\mathrm{dc}}(p)=2\left(R_{\mathrm{c}}+p L_{\mathrm{c}}\right)+\frac{Z_{\mathrm{d}}(p)}{\left(G_{\mathrm{c}}+p C_{\mathrm{c}}\right) Z_{\mathrm{d}}(p)+1} .
$$

\section{Simulations AND MEASUREMENTS ON INDUCTION Mo- TOR DRIVE}

A great amount of simulations and measurements have been carried out for confirmation of the validity of the models and provide a deeper view into the effects. The responses obtained on this model well correspond with the responses captured on the real drive system.

Fig. 6 shows the measured (a) and calculated (b) transient current responses of the IM (a voltage step of $10 \mathrm{~V}$ was applied) in the common mode. The shapes of both responses are in a good agreement. 


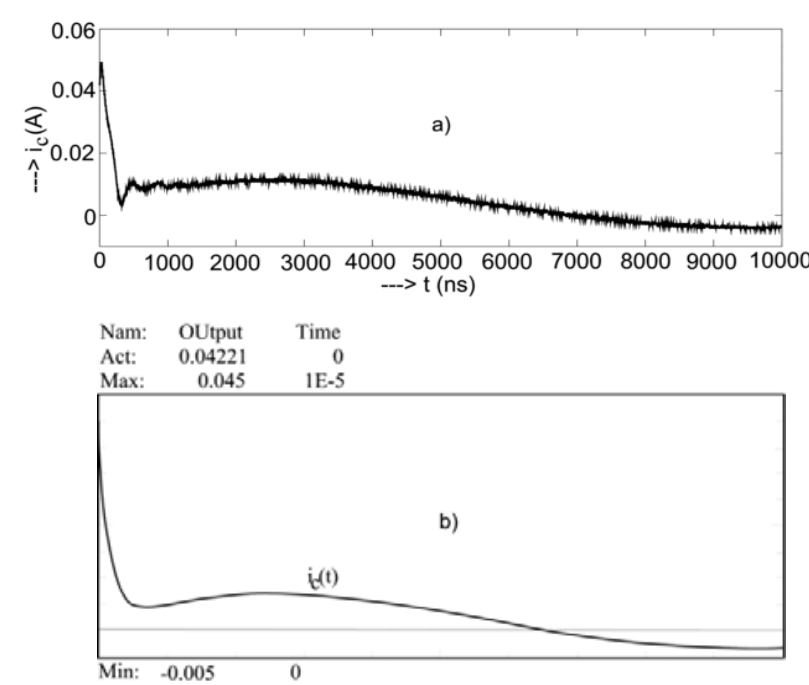

Fig. 6. Common mode current responses of IM: a) measured, b) calculated

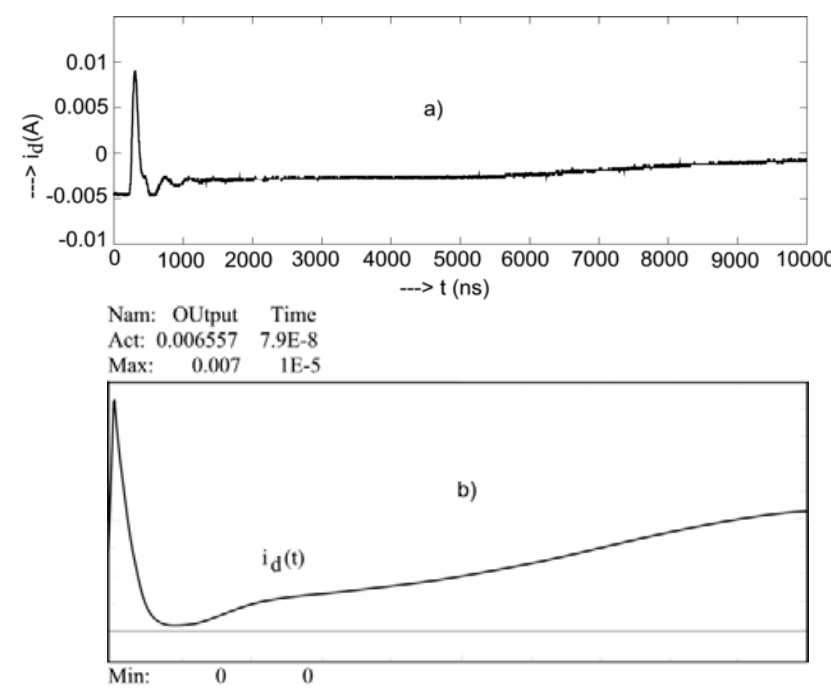

Fig. 7. Differential mode current responses of IM: a) measured, b) calculated

Fig. 7 presents the current responses in the differential mode. The difference between the magnitudes of the measured and calculated peak values of $i_{\mathrm{d}}(t)$ is in accordance with the error in $Z_{\mathrm{d}}(p)=R_{\mathrm{d}}+\mathrm{j} \cdot X_{\mathrm{d}}$ for the lower resonant frequency (Fig. 5). Nevertheless, the shape of the calculated response is in accordance with the measured one.

A lot of computations based on (3)-(4) were also carried out to investigate the common and differential mode current responses if the drive is fed by a series of perfectly trapezoidal voltage pulses drawn from the inverter.

As for the calculated response, the measured values of the inductance and capacitance of the cable are almost constant within the considered range of frequencies and their average values were found to be $L_{\mathrm{c}}^{\prime}=2 \cdot 10^{-6} \mathrm{H} / \mathrm{m}$ and $C_{\mathrm{c}}^{\prime}=1.6 \cdot 10^{-6} \mathrm{~F} / \mathrm{m}$, respectively. Conductance $G_{\mathrm{c}}^{\prime}$ is, as obvious, far from being constant and grows with frequency, but as in comparison with $\omega C_{\mathrm{c}}^{\prime}$ is always too small, its value was taken $10^{-8} \mathrm{~S} / \mathrm{m}$. Finally $R_{\mathrm{c}}^{\prime}(\Omega / \mathrm{m})$ is strongly dependent on frequency and was approximated by function

$$
R_{\mathrm{c}}^{\prime}(f)=R_{\mathrm{c} 0}+k f^{2}
$$

where relevant measurements provided values $R_{\mathrm{c} 0}=0.02 \Omega / \mathrm{m}$ and $k=0.28 \cdot 10^{-12} \Omega \mathrm{m}^{-1} \mathrm{~s}^{-2}$.

$\mathrm{t} 1=0.20$ mics, $\quad \mathrm{t} 2=24.80$ mics, $\quad \mathrm{t} 3=0.20$ mics, $\quad \mathrm{t} 4=24.80 \mathrm{mics}_{1} \quad \mathrm{U}=10.0 \mathrm{~V}$. $R=0.02000 \mathrm{hm} / \mathrm{m}, \quad L=2.0000 \mathrm{mich} / \mathrm{m}_{1} \quad C=0.1600 \mathrm{nF} / \mathrm{m}_{1} \quad G=10.0 \mathrm{nS} / \mathrm{m}_{1} \quad I=1.0 \mathrm{~m}$,
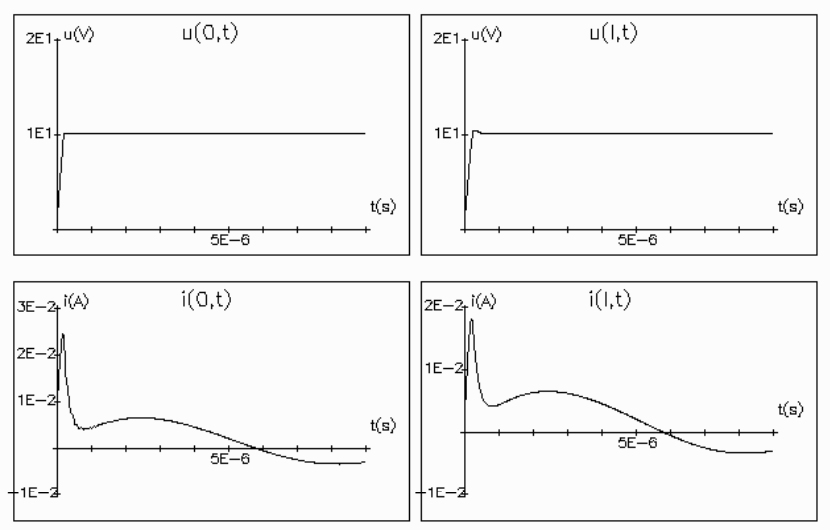

a) cable length $1 \mathrm{~m}$

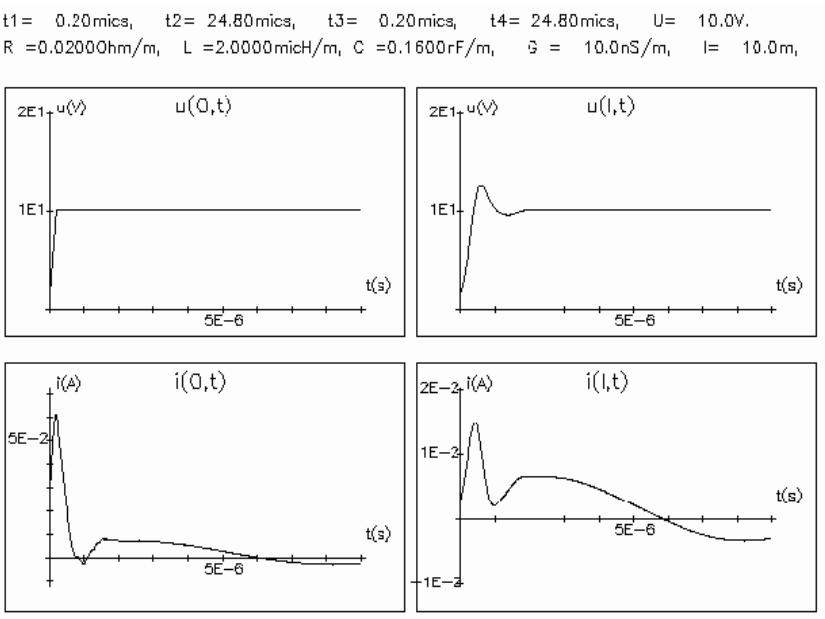

b) cable length $10 \mathrm{~m}$

Fig. 8. Calculated voltage and common mode current responses at system with feeding cable and IM

Fig. 8a) shows the steady state values of voltage and common mode current responses at the beginning (left hand side) and the end (right hand side) of the cable of the length of $1 \mathrm{~m}$, Fig. 8 b) presents similar values for the cable of length of 10 $\mathrm{m}$. By comparing the figures we can see how the overvoltages at motor terminals are higher, as a result of wave phenomena, and the current peaks at inverter terminals more pronounced, due to cable leakage currents, for the longer cable.

Fig. 9 compares the calculated (the number of the Fourier expansion terms being 500) and measured transient common mode current responses in a system with the feeding cable of length $10 \mathrm{~m}$ and IM.

Fig. 10 shows the common mode interference spectra detected at the measurement point at the LISN and expressed in 
the double logarithmic representation for two different lengths of the feeding cables $\left(l_{\mathrm{c}}=2 \mathrm{~m}\right.$ and $\left.30 \mathrm{~m}\right)$. Three characteristics are depicted, namely for only the inverter in operation dotted lines), the IGBT inverter with the feeding cable (dashed lines) and for the inverter feeding the IM through the cable (full lines). By comparing the interference spectra for different lengths of the cable and different parts of the system we can evaluate impacts of these individual subsystems of the drive.

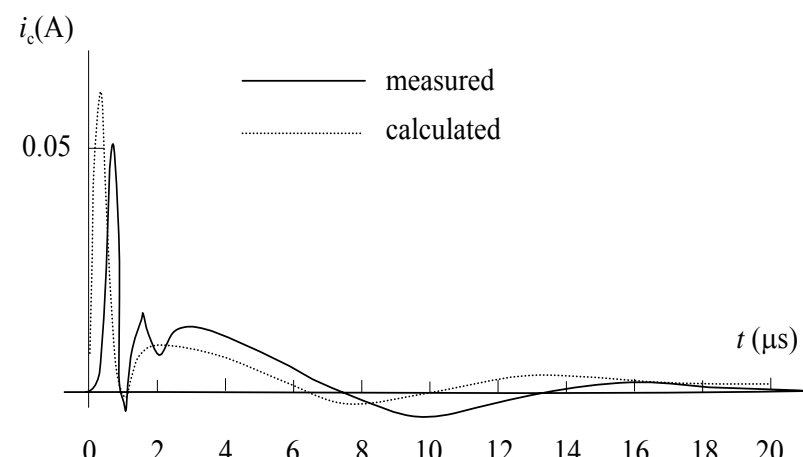

Fig. 9. Calculated and measured current response in the common mode (system with the feeding cable of length $10 \mathrm{~m}$ and IM)
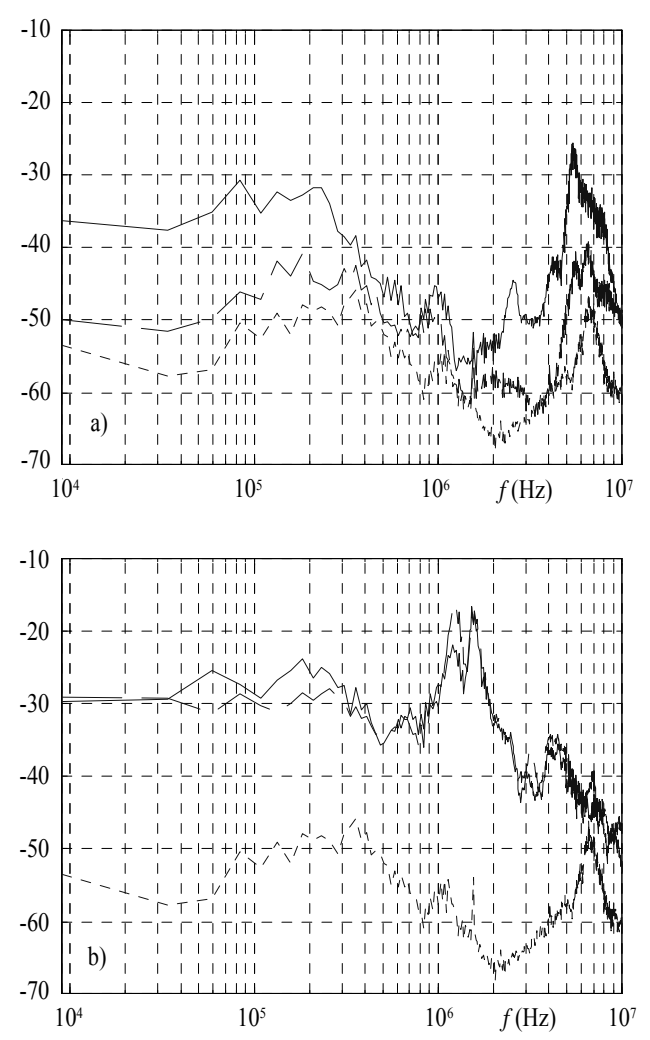

Fig. 10. Common mode interference spectra for a) $l_{\mathrm{c}}=2 \mathrm{~m}$, b) $l_{\mathrm{c}}=30 \mathrm{~m}$

Two main peaks (around $350 \mathrm{kHz}$ and $6.5 \mathrm{MHz}$ ) may be distinguished at the frequency spectrum for the inverter working alone without any load. After comparing the curves in the two figures we can see that the longer is the cable, the higher is the level of the common mode interference (dashed lines), while for the longer cable the spectra measured without and with the induction machine (Fig. 10b) are almost identical.

The reason is that with growing length of the cable the current flowing via the stray capacitances of the cable to ground increases. For a certain length of the cable the contribution of the IM leakage current to the total current is almost negligible, except for the range of lower frequencies (below a few hundreds of $\mathrm{kHz}$ ). It is clearly visible that the character of the spectra (full lines) between 70 and $300 \mathrm{kHz}$ is practically the same irrespective of the lengths of cables feeding the IM. It indicates that this part characterizes the IM. On the contrary, the second dominating part of the characteristics (around 5.5 and $1.5 \mathrm{MHz}$ ) depends on the cable length (2 and $30 \mathrm{~m})$.

As a matter of fact, power switching devices feature permanent improvement which can be demonstrated e.g. by the successive development of GTOs into IGCTs. In general, the objective has been an increase in the device ratings, especially in terms of the repetitive peak blocking voltage (nowadays up to $V_{\mathrm{DRM}}=4500 \mathrm{~V}$ ), the maximum controllable turn-off current (nowadays up to $I_{\mathrm{TGQM}}=4000 \mathrm{~A}$ ) and the device switching frequency. The IGCT is based on the principle that is called the hard-driven turn-off process, which is known also as unity-gain turn-off.

Fig. 11 compares the voltage front edges produced by an IGCT inverter to voltage front edges produced by the IGBT inverter. For this comparison, however, inverters with the same de supply voltage were not at our disposal. The IGBT inverter was made up of a MITSUBISHI module and the provided dc feeding voltage was $310 \mathrm{~V}$. The IGCT inverter, on the other hand, was supplied by $550 \mathrm{~V}$. The supplied motor was an IM of the type TB 702 with rated values $85 \mathrm{~kW}, 75$ $\mathrm{Hz}, 2214 \mathrm{rpm}, 133.8 \mathrm{~A}$.

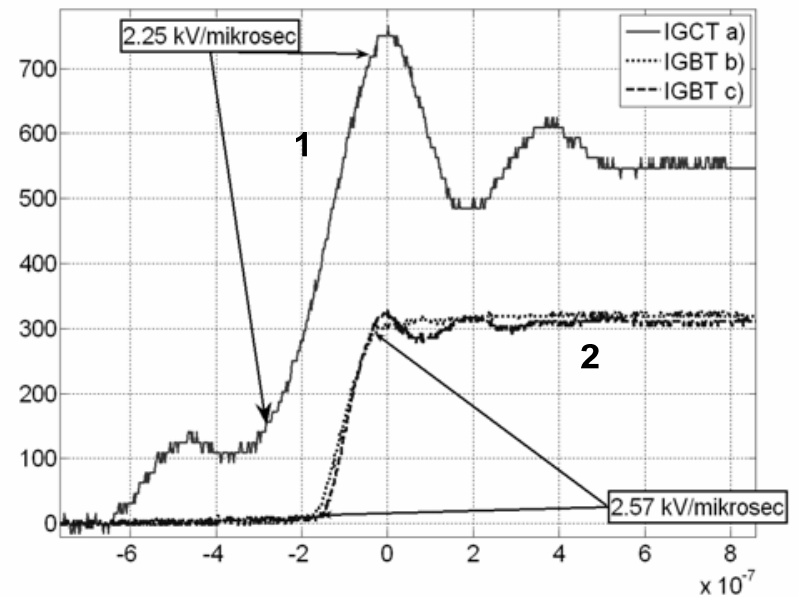

Fig. 1. Comparison of voltage front edges, the voltage across the minus dc input terminal and any of ac outputs, cable length $3 \mathrm{~m}$

1. IGCT inverter: separate phase cables, point of measurement $1 \mathrm{~m}$ distant .from the inverter, 2. IGBT inverter, 3-phase cable employed.)

We see that the voltage front edges at both the IGBT and IGCT inverters have similar steep slopes and, although the switching times at the IGCT-based inverters are longer than those at the IGBT inverters, it may be expected that these inverters will produce also similar voltage waves traveling along the cables connecting the inverters and ac motors and resulting overvoltage phenomena, Fig. 12. 
To eliminate solitary, accidental, and abnormal waveforms, two characteristic waveforms (samples) measured very close to the inverter and two characteristic samples measured very close to the motor were selected for the harmonic analysis. The figure demonstrates that the presence of the cable results in overvoltages at IM terminals.
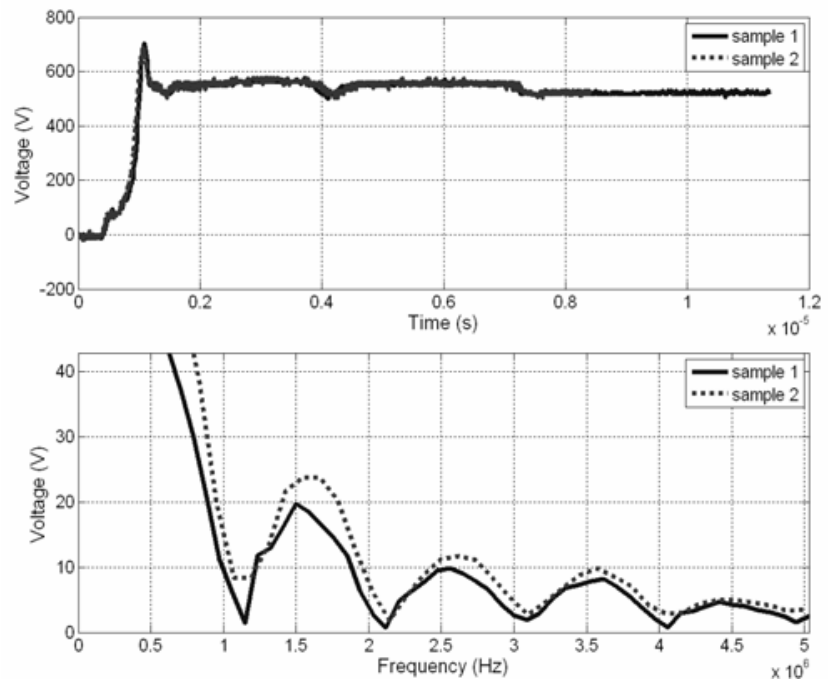

a) close to IGCT inverter
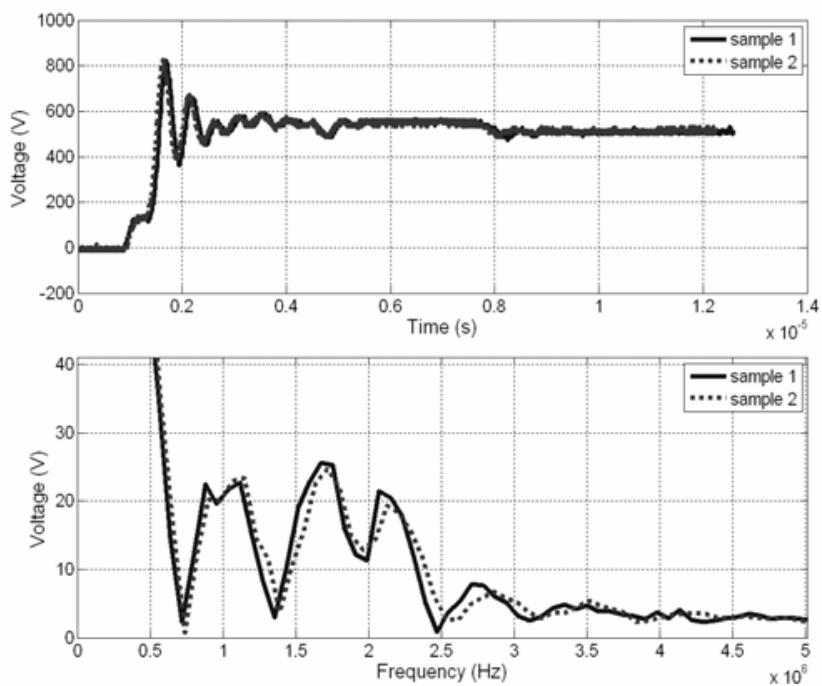

b) close to IM

Fig. 12. Voltage-time, voltage-frequency relationships (IGCT inverter, cable $10 \mathrm{~m}$ long), measured at two different positions

We have found the results and experience referred so far are very useful at the development and testing of some drives of vehicles for city mass transport from the point of view of EMI. In addition to conducted high frequency parasitic currents also radiated EMI produced by the drives of vehicles (tramways and trolleybuses) were calculated and measured.

Fig. 13, 14 present examples of results gained when modeling magnetic field inside and outside the trolleybus TR21. Computation was carried out for various working regimes and for application of two different power switching semiconductor devices (IGBTs, IGCTs). Influence on near low-current and telecommunication systems was of our interest too. Computation of the magnetic field was performed by the professional FEM-based program QUICKFIELD. Results were compared with values measured and those given by standards.

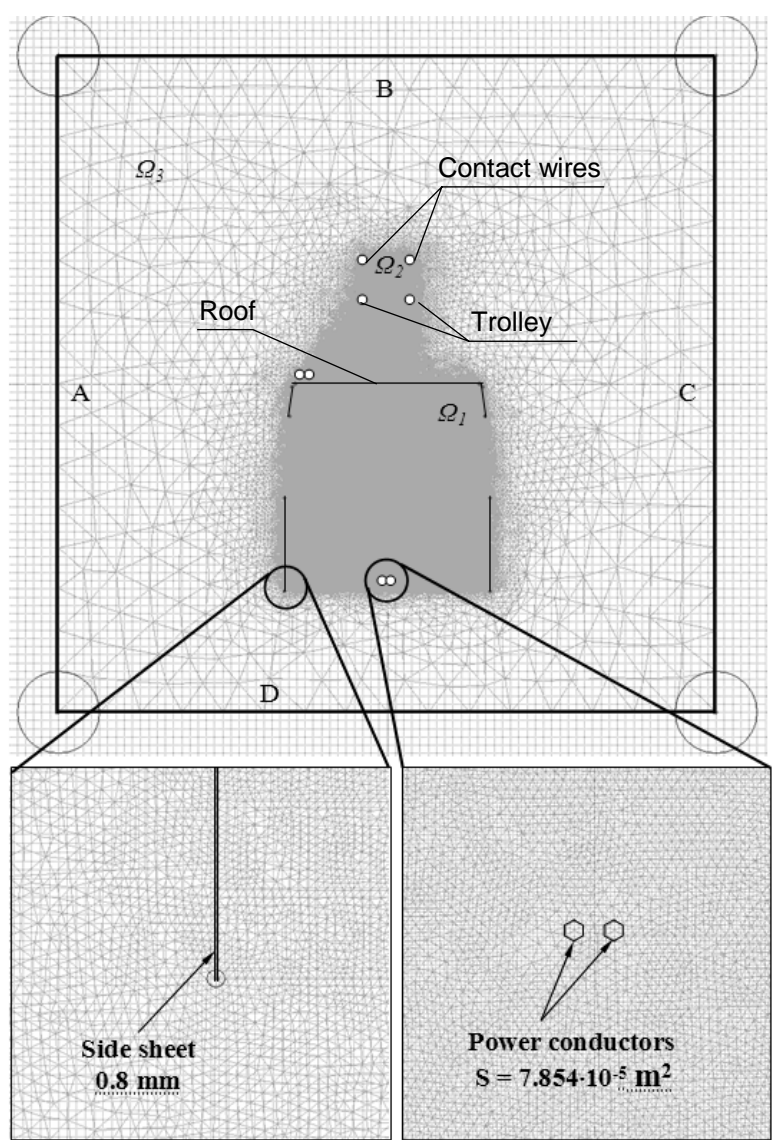

Fig. 13. Calculation of magnetic field inside and outside the trolleybus TR21. Preprocessing. Mesh with details: 379807 notes

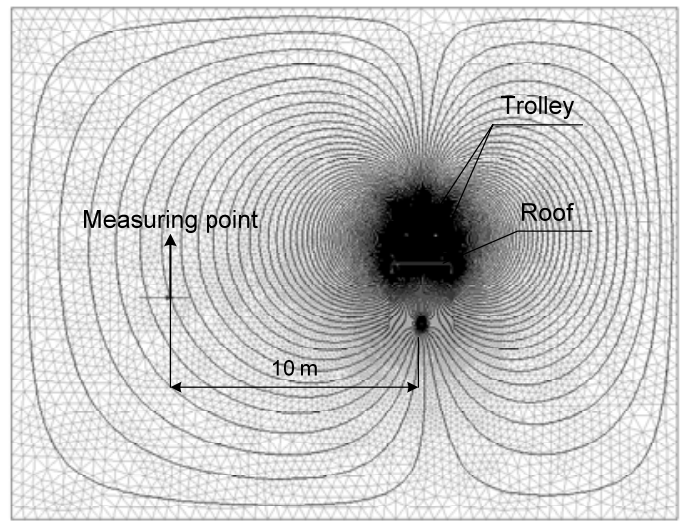

Fig. 14. Contours of calculated intensity of magnetic field inside and outside trolleybus TR21

Figs. 15, 16 show examples of the measured levels of EMI in the city transport enterprises in Czech towns Hradec Králové and Plzeň. It is important to note that at Hradec Králové a trolleybus with IGCT devices was pursued, Fig. 15. The EMI background there was influenced by other trolleybuses, which were operating at the same time. The EMI of a tramway equipped with IGBT inverters was measured at 
Plzeň, Fig. 16. The tramway was a prototype under test operation and no other similar tramways were connected to the overhead contact system. To increase the objectivity, many measurements at various localities were carried out.

The results summarized in Figs. 13-16 were helpful when suggesting measures aimed at the reduction of EMI.

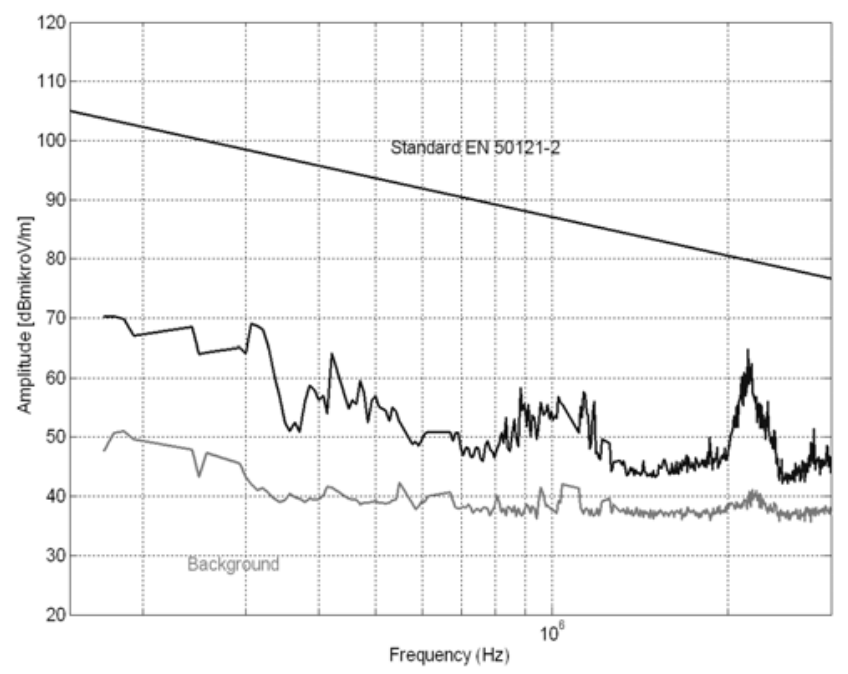

Fig. 15. Values of EMI obtained from the analyzer E7401A at Hradec Králové (trolleybus TR21). The measurements were performed in accordance with the demands (distance of the antenna, etc.) of the Standard EN 50121-2

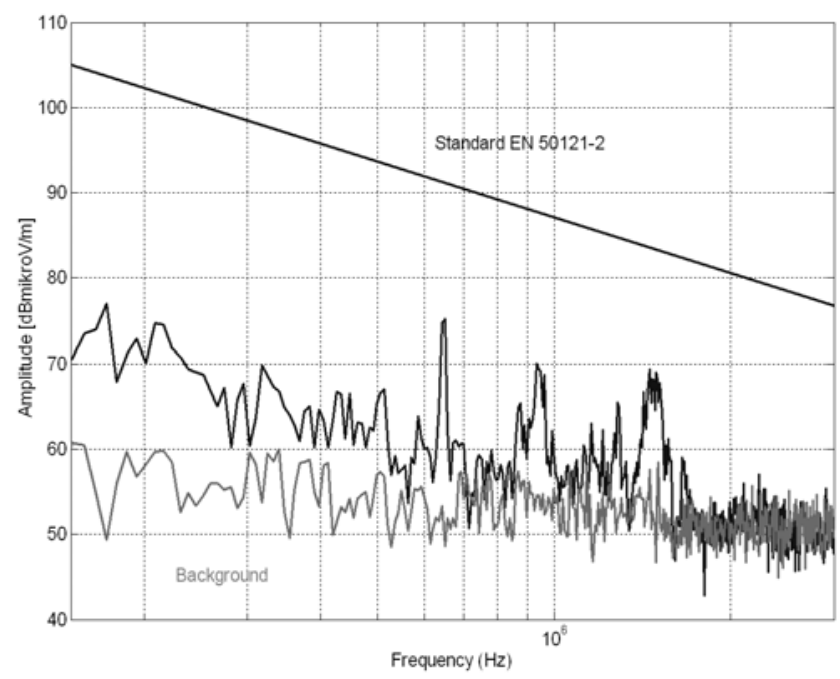

Fig. 16. Values of EMI obtained at Plzeň (tramway equipped with IGBT inverters)

\section{CONCLUSIONS}

The equivalent models of the feeding cable as well as the IM suitable for the determination of stray current disturbances in the common and differential modes have been suggested. The frequency characteristics of selected parts of the system and their contributions to the resultant harmonic spectra have been evaluated as well.

The responses obtained on this model well correspond with the responses captured on the real drive system. This holds even at the very beginning of the transients, where the vari- ables (mainly currents) are characterized by steep changes (peaks) and high frequencies.

As for the IGCT inverters, it has to be expected that these inverters may produce similar voltage waves traveling along the cables connecting the inverters and ac motors and resulting phenomena as those produced by the IGBT inverters, although IGCT total switching times are substantially longer.

The paper summarizes also the experience acquired during laboratory experimental operation of the IGBT and IGCT inverter feeding a 3-phase induction machine (IM) as well as practical knowledge gained from the employment of these switching devices in vehicles of city mass transportation.

\section{ACKNOWLEDGMENT}

The financial supports of the Grant Agency of the Czech Republic (Project No. 102/06/0112) and the Academy of Sciences of the Czech Republic (Institutional Research Plan Z20570509 of the Institute of Thermomechanics, v.v.i.) are gratefully acknowledged.

\section{REFERENCES}

[1] Van der Broeck H., Loef Chr.: Use of LC Filters in Hard Switching PWM Inverter Drives. Proceedings of EPE'95 Conference, pp. 1536 -1541, Sevilla, Spain (1995).

[2] Von Jouanne A., Rendusara D.A. Enjeti P.N., Gray J.W.: Filtering Techniques to Minimise the Effects of Long Motor Leads on PWM Inverter-Fed AC Motor Drive Systems. IEEE Transactions on IA 32, No. 4 , pp. 919 - 925 (1996).

[3] Ogasawara S., Akagi H.: Modelling and Damping of High-Frequency Leakage Currents in PWM Inverter-Fed AC Motor Drive Systems. IEEE Transactions on IA 32, No. 5, pp. 1105 -1113 (1996).

[4] N. Mutoh and M. Ogata, New Methods to Control EMI Noises Generated in Motor Drive Systems, IEEE Trans. on IA, Vol. 40, No.1, 2004, pp. 143-152.

[5] Persson E.: Transient Effects in Application of PWM Inverters to Induction Motors. IEEE Transactions on IA 28, No. 5, pp. 1095 - 1101 (1992).

[6] Cacciato M., Consoli A., Scarcella G., Testa A. Effects of PWM Techniques on Common Mode Currents in Induction Motor Drives. Proceedings of ISIE'97 Symposium, pp. SS212-SS217, Guimarães, Portugal (1997).

[7] Consoli A., Oriti G., Testa A., Julian A.L.: Induction Motor Modeling for Common Mode and Differential Mode Emission Evaluation. Conference record of the 31st IAS Annual Meeting, pp. 595 - 599, San Diego, USA (1996).

[8] Grandi G., Casadei D., Reggiani U.: Equivalent Circuit of Mush Wound AC Windings for High Frequency Analysis. Proceedings of ISIE'97 Symposium, pp. SS201 - SS206, Guimarães, Portugal (1997).

[9] Kerkman R.J., Leggate D., Skibinski G.L.: Drive Modulation and Cable Parameters on AC Motor Transients. IEEE Transactions on IA 33, No. 3 , pp. 722 - 729 (1997).

[10] H. Akagi and S. Tamura, A Passive EMI Filter for Eliminating Both Bearing Current and Ground Leakage Current From an Inverter-Driven Motor, IEEE Trans. on PE, Vol. 21, No. 5, 2006, pp. 1459-1469.

[11] G. Grandi, D. Casadei and U. Reggiani, Equivalent Circuit of Mush Wound AC Windings for High Frequency Analysis, Proc. ISIE'97, Guimarães, Portugal, 1997, pp. SS201-SS206.

[12] A. Boglietti and E. Carpaneto, An Accurate Induction Motor HighFrequency Model for Electromagnetic Compatibility Analysis, Electric Power Components and Systems, Taylor\&Francis, Vol. 29, 2001, pp. 191-209.

[13] J. S. Lai, X. Huang, E. Pepa, S. Chen and T. W. Nehl, Inverter EMI Modeling and Simulation Methodologies, IEEE Trans. on IE, Vol. 53, No.3, 2006, pp. 736-744. 